\title{
Self-assembled supramolecular hydrogel based on PCL-PEG-PCL triblock copolymer and $\gamma$-cyclodextrin inclusion complex for sustained delivery of dexamethasone
}

\author{
Elham Khodaverdi, Marzieh Gharechahi ${ }^{1}$, Mona Alibolandi' ${ }^{2}$, Farnaz Sadat Mirzazadeh Tekie ${ }^{3}$, \\ Bibi Zahra Khashyarmanesh ${ }^{4}$, Farzin Hadizadeh ${ }^{2,4}$ \\ Targeted Drug Delivery Research Centre, ${ }^{1}$ Department of Pharmaceutics, ${ }^{2}$ Biotechnology Research Centre and ${ }^{4}$ Department of Medicinal \\ Chemistry, School of Pharmacy, Mashhad University of Medical Sciences, Mashhad, ${ }^{3}$ Medical Nanotechnology Research Centre, Tehran \\ University of Medical Sciences, Tehran, Iran
}

\begin{abstract}
In this study, thermosensitive, water-soluble, and biodegradable triblock copolymer $\mathrm{PCL}_{600}-\mathrm{PEG}_{6000}-\mathrm{PCL}_{600}$ was used to form supramolecular hydrogel (SMGel) by inclusion complexation with $\gamma$-cyclodextrin $(\gamma$-CD). The prepared SMGel was investigated as a carrier for sustained release of dexamethasone. The triblock copolymer PCL-PEG-PCL [where $\mathrm{PCL}=$ polycaprolactone, $\mathrm{PEG}=$ poly(ethylene glycol)] was synthesized by the ring-opening polymerization method using microwave irradiation. The polymerization reaction and the copolymer structures were evaluated by nuclear magnetic resonance (NMR) and gel permeation chromatography (GPC). SMGel was prepared in aqueous solution by blending an aqueous $\gamma$-CD solution with aqueous solution of PCL-PEG-PCL triblock copolymer at room temperature. The sol-to-gel transition time was measured at various concentrations of copolymer and $\gamma$-CD. As-prepared SMGel was used to prepare a sustained, controllable drug delivery system of dexamethasone sodium phosphate. The SMGel was also characterized in terms of rheological, morphological, and structural properties. Results obtained from proton nuclear magnetic resonance $\left({ }^{1} \mathrm{H}-\mathrm{NMR}\right)$ and $\mathrm{GPC}$ demonstrated that microwave irradiation is a simple and reliable method for synthesis of PEG-PCL copolymer. The SMGel with excellent syringability was prepared by mixing of $20 \%$ wt $\gamma$-CD and $10 \%$ wt of copolymer within 4 s. The SMGel containing $10 \%$ wt copolymer, $20 \%$ wt $\gamma$-CD, and $0.5 \%$ or $0.1 \%$ wt dexamethasone released approximately $100 \%$ and $45 \%$ of drug over up to 23 days, respectively. It could be concluded that SMGel based on self-assembly of inclusion complexes between PCL-PEG-PCL copolymer and $\gamma$-CD could be used as a basis for injectable drug delivery systems that provide sustained and controlled release of macromolecular drugs such as dexamethasone.
\end{abstract}

Key words: $\gamma$-cyclodextrin $(\gamma$-CD), dexamethasone, PEG-PCL, supramolecular hydrogel (SMGel)

\section{Address for correspondence:}

Prof. Farzin Hadizadeh,

Biotechnology Research Center, School of Pharmacy,

Mashhad University of Medical Sciences, PO Box. 9196773117,

Mashhad, Iran.

E-mail: hadizadehf@mums.ac.ir

\begin{tabular}{|l|l|}
\hline \multicolumn{2}{|c|}{ Access this article online } \\
\hline Quick Response Code: & Website: \\
\hline & \\
\cline { 2 - 2 }
\end{tabular}

\section{INTRODUCTION}

Controlled drug delivery systems have been designed to keep a plasma concentration of drugs within a therapeutic level for a longer period of time to ensure efficient therapeutic effect. ${ }^{[1]}$

This is an open access article distributed under the terms of the Creative Commons Attribution-NonCommercial-ShareAlike 3.0 License, which allows others to remix, tweak, and build upon the work non-commercially, as long as the author is credited and the new creations are licensed under the identical terms.

For reprints contact: reprints@medknow.com

How to cite this article: Khodaverdi E, Gharechahi M, Alibolandi M, Tekie FS, Khashyarmanesh BZ, Hadizadeh F. Self-assembled supramolecular hydrogel based on PCL-PEG-PCL triblock copolymer and $\gamma$-cyclodextrin inclusion complex for sustained delivery of dexamethasone. Int J Pharma Investig 2016;6:78-85. 
In the past two decades, polymeric hydrogels have been widely investigated as controlled drug delivery systems because of their high water content, generally favorable biocompatibility, and easy preparation. ${ }^{[2-5]}$

The formation of supramolecular systems is mainly organized by means of intermolecular noncovalent binding interactions between two or more molecular moieties. ${ }^{[6]}$

Counted among the most potent classes of biomaterials, supramolecular hydrogels (SMGels) formed by cyclodextrins (CDs) and linear polymers have been employed as controllable drug delivery systems. ${ }^{[7,8]}$

CDs are a series of cyclic oligosaccharides composed of 6 $(\alpha-C D), 7(\beta-C D)$, or $8(\gamma-C D), D(+)$-glucose units linked by $\alpha 1,4$-linkages. ${ }^{[9]}$

The geometry of CDs gives a hydrophobic inner cavity having a depth of ca. $7 \mathrm{~A}^{\circ}$, and an internal diameter of ca. $4.5 \mathrm{~A}^{\circ}, 7 \mathrm{~A}^{\mathrm{o}}$, and $8.5 \mathrm{~A}^{\circ}$ for $\alpha-, \beta$-, and $\gamma$-CD, respectively. ${ }^{[10]}$

Due to the capability of forming inclusion complexes in the inner cavities and exceptional physicochemical characteristics, CDs have been utilized in drug delivery systems to improve solubilization, stabilization, and absorption. ${ }^{[1]}$

The first noteworthy report on the preparation of CD-based polyrotaxanes described the SMGel composed of multiple $\alpha$-CD rings threading on a poly (ethylene oxide) chain and trapped by end-capping the chain with bulky end groups. ${ }^{[12]}$

Since then, many studies has been focused on the evaluation of supramolecular structures based on the polyrotaxanes and the polypseudorotaxanes formed by CDs threading on a polymer chain $^{[13-17]}$ and their applications in medicine. ${ }^{[18-22]}$

SMGels are used as controlled drug delivery systems for a variety of applications including chemotherapy, cardiovascular disease, hormone therapy, therapeutic protein delivery, and vaccine development. ${ }^{[23-25]}$

A drug delivery formulation can be obtained by physical hydrogels, by which gelation and high drug loading can be achieved simultaneously in an aqueous environment without chemical crosslinking, during sol-to-gel transition. Furthermore, the stimuli-responsive properties of hydrogels provide the essential intelligence required for drug delivery and release. ${ }^{[26]}$

Glucocorticoids such as dexamethasone emerged as a type of potent medicine to prevent or suppress inflammation in response to multiple inciting events, including infectious, immunological, mechanical, and chemical stimuli. ${ }^{[27]}$

Dexamethasone in multiple dosage form has serious systemic side effects. Consequently, the controlled, continuous delivery of dexamethasone using SMGel was considered to avoid these side effects and achieve the goal of suppressing inflammatory responses. Some of the advantages of SMGels as controlled drug delivery vehicle are: A decrease in dosage of the formulation, a sustained continuous drug release, decrease side effects, reduced frequency of administration, and, therefore, increased patient compliance. ${ }^{[28]}$

We reported the sol-gel transition during self-assembling induced by inclusion complexation between $\gamma$-CD and PCL-PEG-PCL triblock copolymer with the PEG/PCL ratio of $1 / 5$ in aqueous solution. ${ }^{[26]}$

The objective of this study was to develop a SMGel system that can be used for sustained, continuous delivery of an antiinflammatory drug using a simple preparation method that had shown promising preliminary in vitro results in our laboratory.

\section{MATERIALS AND METHODS}

\section{Generals}

Poly (ethylene glycol) (i.e., PEG) with molecular weights of 6000 was purchased from Merck (Darmstadt, Germany). Poly$\varepsilon$-caprolactone (i.e., PCL) and stannous octanoate [Tin(II) ethylhexanoate or $\mathrm{Sn}(\mathrm{Oct} 2)]$ were procured from Sigma Aldrich (Missouri, USA). y-CD was purchased from Fluka (Buchs, Switzerland).

Dexamethasone sodium phosphate was kindly donated by DarouPakhsh (Tehran, Iran). All other analytical-grade chemical reagents and solvents were obtained from Merck (Germany) and used as received.

\section{Synthesis of triblock copolymer}

PCL-PEG-PCL copolymers were synthesized with the PCL:PEG ratio of 1:5 by ring-opening polymerization technique using microwave irradiation, as described previously. ${ }^{[29]}$

Briefly, PEG $10 \mathrm{~g}$ was introduced into a round-bottom flask equipped with a condenser and this was placed in a microwave instrument. The PEG was irradiated for $10 \mathrm{~min}$ at $800 \mathrm{~W}$ and $130^{\circ} \mathrm{C}$. Then to the dried viscous PEG, $2 \mathrm{~g}$ PCL and catalyst $\mathrm{Sn}(\mathrm{Oct})_{2}$ were added and the mixture was irradiated and stirred at $800 \mathrm{~W}$, while the temperature was kept at $130^{\circ} \mathrm{C}$ for $15 \mathrm{~min}$.

The synthesized copolymer was purified by dissolving the product in $30 \mathrm{~mL}$ dichloromethane followed by precipitating by adding $800 \mathrm{~mL}$ diethyl ether. The purification process was repeated three times, and the precipitate was freeze-dried and kept at $-20^{\circ} \mathrm{C}$ until use.

The yield of the reaction was calculated by dividing the amount of the obtained product by the amount of the starting materials used in the copolymer synthesis process. 


\section{Characterization of PCL-PEG-PCL triblock copolymer}

The proton nuclear magnetic resonance ( $\left.{ }^{1} \mathrm{H}-\mathrm{NMR}\right)$ spectrum of the synthesized PCL-PEG-PCL triblock copolymer was recorded by Bruker Ac-80 spectrophotometer (Ettlingen, Germany) in $\mathrm{CDCl}_{3}$ at $25^{\circ} \mathrm{C}$.

The number average molecular weight $\left(\mathrm{M}_{\mathrm{n}}\right)$ and the PEG/PCL ratio were estimated by integrating the signals pertaining to each monomer, such as the peaks from $\mathrm{CH}_{2}$ of ethylene glycol and $\mathrm{CH}_{2}$ of PCL according to the method established by Jeong et al. ${ }^{[30]}$

The molecular weight $\left(\mathrm{M}_{\mathrm{w}}\right)$ and polydispersity of the synthesized copolymer was determined by gel permeation chromatography (GPC)s, using the Agilent GPC-Addon system (California, USA) and RID-A refractive index signal detector (Agilent Technology, California, USA) coupled to PLgel. Tetrahydrofuran was used as an eluent with a flow rate of $1 \mathrm{~mL} / \mathrm{min}$ and the sample injection volume was $10 \mu \mathrm{L}$.

\section{Formation and characterizations of SMGels}

Aqueous solutions with various concentrations of PCL-PEGPCL: $1.5 \%, 2 \%, 2.5 \%, 10 \%, 15 \%, 20 \%, 25 \%$ (w/v) and of $\gamma$-CD: $8 \%, 10 \%, 12 \%, 15 \%, 20 \%, 25 \%$ (w/v) were mixed with vigorous stirring until the formation of hydrogels at room temperature up to $24 \mathrm{~h}$.

To determine whether the SMGels formed, the vials were inverted, and when the mixture did not flow, it was assumed to be the gel formation time.

To prepare dexamethasone-loaded SMGel, $0.1 \%$ and $0.5 \%(\mathrm{w} / \mathrm{v})$ of dexamethasone sodium phosphate was dissolved in $10 \%(\mathrm{w} / \mathrm{v})$ aqueous solution of PCL-PEG-PCL copolymer. Then an equal volume of $20 \%(\mathrm{w} / \mathrm{v}) \gamma$-CD solution was gradually added to the solution of drug and copolymer under vigorous stirring.

\section{Investigation of SMGel and physical mixture morphology}

The structure of freeze-dried dexamethasone-loaded SMGel and the physical mixture of copolymer/ $\gamma$-CDs/dexamethasone were analyzed by scanning electron microscopy (SEM) using a LEO1350 VP equipment (Selb, Germany). The powder samples were mounted on double-sided carbon adhesive tape on aluminum stubs and coated with 2-5-nm gold layers, which were processed in a standard sputter under vacuum. Then the microstructures of the samples were investigated.

\section{Swelling ratio measurement}

To evaluate the swelling ratio of SMGel, $100 \mathrm{mg}$ of dried hydrogel was immersed in $250 \mathrm{~mL}$ deionized water at room temperature. The mass of sample was measured after removal of surface waters every $15 \mathrm{~min}$ for three times. When SMGel reached the maximum state of swelling state, a swelling ratio was calculated using the following equation: ${ }^{[31]}$

Swelling ratio $=($ Wet weight Dry weight $) /$ Dry weight $(1)$

\section{X-ray powder diffraction (XRPD)}

The XRPD study was carried out to characterize the crystalline phase of the dexamethasone-loaded SMGel and the physical mixture of $\gamma$-CD/copolymer/dexamethasone. A Phillips analytical $x$-ray B.V. (Almelo, The Netherlands) was used as an $\mathrm{x}$-ray generator consisting of a PW3710 diffractometer and an $\mathrm{x}$-ray tube $(30 \mathrm{~mA}$ and $40 \mathrm{kV})$ with a copper anode. Data were collected in continuous scan mode using a step size of $0.033^{\circ}$ 2q. The scanned range was $0^{\circ}$ to $70^{\circ}$.

\section{Differential scanning calorimetric (DSC)}

DSC scans of about 3-5 mg of accurately weighed SMGel, dexamethasone-loaded SMGel, dexamethasone, triblock copolymer, and $\gamma$-CD were performed by an automatic thermal analyzer system (Mettler Toledo DSC 822, Greifensee, Switzerland). Each sample put into the sealed aluminum-lead pans was run at a scanning rate of $20^{\circ} \mathrm{C} / \mathrm{min}$ from $0{ }^{\circ} \mathrm{C}$ to $300^{\circ} \mathrm{C}$.

\section{Evaluation of formulation injectability}

Syringe with a 25-gauge microfine needle was filled with dexamethasone-loaded SMGel, and the injectability of the formulations was determined by passing through the syringe at $25^{\circ} \mathrm{C}$.

\section{Evaluating the rheological behavior of the SMGel}

The viscoelastic behavior of the SMGel containing $10 \% \mathrm{w} / \mathrm{v}$ copolymer and $20 \% \mathrm{w} / \mathrm{v} \gamma$-CD was evaluated on an R/S plus Mo8219 rheometer (Brookfield, Middleboro, USA). The viscosity of the hydrogel was recorded applying a flow cycle consisting of a continuously increasing shear rate ramp at $25^{\circ} \mathrm{C}$.

Then, the logarithm of related viscosity and shear stress plotted against shear rate to evaluate the thixotropic behavior of the hydrogel.

\section{In vitro release study}

$1 \mathrm{~mL}$ of formulation was poured into $10 \mathrm{~mL}$ tubes with a cross-sectional area of $1 \mathrm{~cm}^{2}$ containing $3 \mathrm{~mL}$ phosphate-buffered saline (PBS, $\mathrm{pH}=7.4$ ) solution. The tubes were then transferred to a water bath shaker incubator (FarazTeb, Tajhiz, Iran) set at $50 \pm 2 \mathrm{rpm}$ and $37^{\circ} \mathrm{C}$.

Samples $(500 \mu \mathrm{L})$ were withdrawn at definite times and replaced by addition of $500 \mu \mathrm{L}$ of fresh PBS, $\mathrm{pH}=7.4$.

The samples were assayed for dexamethasone content by high-performance liquid chromatography (HPLC).

Analytical HPLC was performed by Waters 600 pump system (Waters Corporation, Milford, MA, USA) on a Novapak C18 column $\left(3.9 \times 150 \mathrm{~mm}^{2}\right)$. An isocratic solvent consisting of acetonitrile/PBS (10 $\mathrm{mM}) 70 / 30$ was used as a mobile phase with a flow rate of $1 \mathrm{~mL} / \mathrm{min}$ at $25^{\circ} \mathrm{C}$.

The amount of dexamethasone eluted from the column was recorded on UV-vis $(\lambda=242 \mathrm{~nm})$ using a Waters 2487 dual 
absorbance detector. The volume of each injection was $30 \mu \mathrm{L}$ and each sample was analyzed three times. Data were analyzed using AzurV.4.0 software (Datalys, Theix, France). ${ }^{[32]}$

\section{RESULTS AND DISCUSSION}

\section{PCL-PEG-PCL synthesis and characterizations}

The copolymer was successfully synthesized by ring-opening polymerization with a yield of $88 \%$. Such a high yield of reaction indicated the efficiency of the microwave-assisted method in synthesis of PCL-PEG-PCL, as also reported before. Moreover, as by this method lower amounts of impurities emerge in comparison with the conventional synthesis method, a shorterpurification procedure was needed, therefore less waste of products occurred along with the purification.

The ${ }^{1} \mathrm{H}-\mathrm{NMR}$ spectrum of the PCL-PEG-PCL copolymer is represented in Figure 1.

The signal at $3.6 \mathrm{ppm}$ is attributed to the $\mathrm{CH}_{2}$ of the PEG block in the copolymer chains, and its integral was used as an internal standard to calculate the number average chain length of the PEG.

The signals at $4.1 \mathrm{ppm}, 2.2 \mathrm{ppm}$, and $1.5 \mathrm{ppm}$ are related to the $\mathrm{CH}_{2}$ of PCL block and with their integrals the number average chain length of the PCL can be estimated.

The obtained results verify that microwave irradiation is a reliable method for synthesis of PCL-PEG-PCL triblock copolymer.

The GPC chromatogram of the synthesized copolymer is shown in Figure 2. The GPC curve of the copolymer is symmetrical, indicating the negligible polydispersity of the polymer. No shoulder peaks corresponding to the PCL macromere or its homopolymer were detected.

Table 1 shows the number average molecular weight $(\mathrm{Mn})$, the molecular weight $(\mathrm{Mw})$, and the molecular weight distribution

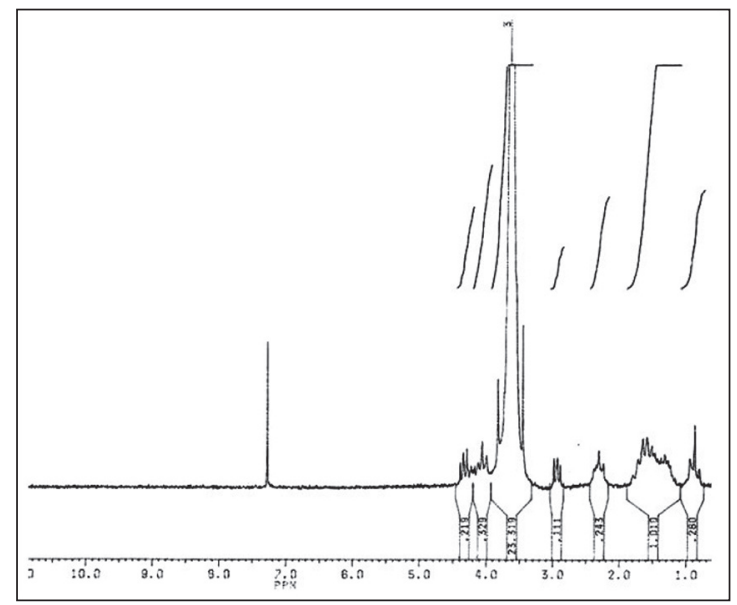

Figure 1: ${ }^{1} \mathrm{H}-\mathrm{NMR}$ of $\mathrm{PCL}_{600}-\mathrm{PEG}_{6000}-\mathrm{PCL}_{600}$ triblock copolymer of copolymers which was determined by GPC and ${ }^{1} \mathrm{H}-\mathrm{NMR}$. The PEG/PCL ratio is very close to the intended ratio used in the reaction initially. It shows that reaction proceeded well to produce the purposed triblock copolymer.

\section{SMGel formation}

PCL-PEG-PCL triblock copolymer with short PCL block (600 Da) was found to form hydrogel complexes with at least $20 \% \mathrm{w} / \mathrm{v}$ of $\gamma$-CD and $10 \% \mathrm{w} / \mathrm{v}$ of copolymer.

In our study, the effects of the copolymer and $\gamma$-CD concentrations on hydrogel formation were investigated.

Table 2 represents the formulations that turned into the gel and the length of time they took to come into shape at $25^{\circ} \mathrm{C}$. The formulations that were able to turn into a gel remained in gel form at $37^{\circ} \mathrm{C}$. Among the tested formulations, only the aqueous solution containing $10 \%$ and $20 \%(\mathrm{w} / \mathrm{v})$, and the one containing

Table 1: Copolymer characteristics determined by ${ }^{1} \mathrm{H}-\mathrm{NMR}$ and GPC

\begin{tabular}{|c|c|c|c|c|}
\hline \multicolumn{2}{|c|}{${ }^{1} \mathrm{H}-\mathrm{NMR}$} & \multicolumn{3}{|c|}{ GPC } \\
\hline $\mathrm{Mn}^{\mathrm{a}}$ & PEG/PCL ${ }^{b}$ & $M n^{c}$ & $M w^{d}$ & $\mathbf{M w} / \mathbf{M n}^{e}$ \\
\hline $\begin{array}{l}\mathrm{PCL}_{732}{ }^{-} \\
\mathrm{PEG}_{6000}-\mathrm{PCL}_{732}\end{array}$ & 0.24 & 6120 & 5895 & 0.96 \\
\hline
\end{tabular}

aNumber average molecular weight determined by ${ }^{1} \mathrm{H}-\mathrm{NMR}$, ${ }^{\mathrm{b}} \mathrm{PCL} / \mathrm{PEG}$ ratio determined by ${ }^{1} \mathrm{H}-\mathrm{NMR}$, ${ }^{\mathrm{C}}$ Number average molecular weight determined by GPC, ${ }^{d}$ Average molecular weight determined by GPC, ePolydispersity determined by GPC

Table 2: SMGel preparation at $25^{\circ} \mathrm{C}$ with various concentrations of copolymer and $\gamma-C D$

\begin{tabular}{lllllll}
\hline $\begin{array}{l}\gamma-C D \\
\text { Copolymer } \\
(\%)\end{array}(w / v)$ & $\mathbf{8}$ & 10 & 12 & 15 & 20 & 25 \\
\hline 1.5 & - & - & - & $\begin{array}{l}\text { No gel } \\
\text { No gel }\end{array}$ & No gel \\
2 & - & - & - & $\begin{array}{l}\text { No gel } \\
\text { No gel }\end{array}$ & No gel \\
2.5 & No gel & No gel & No gel & No gel & No gel & Gel in 8 s \\
10 & No gel & No gel & No gel & No gel & Gel in & - \\
15 & No gel & No gel & No gel & - & - & - \\
20 & No gel & No gel & No gel & - & - & - \\
25 & No gel & No gel & No gel & - & - & - \\
\hline
\end{tabular}

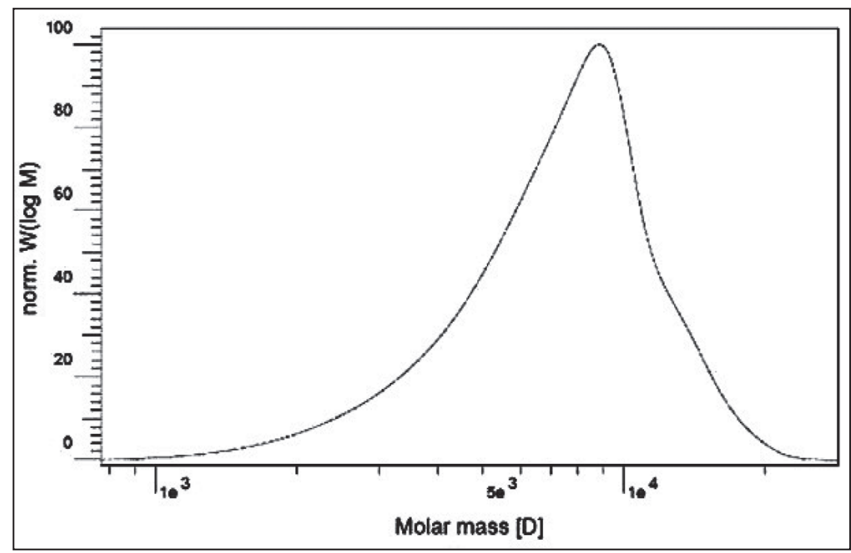

Figure 2: GPC chromatogram of the PCL-PEG-PCL 
$2.5 \%$ and $25 \%(\mathrm{w} / \mathrm{v})$ of copolymer and $\gamma$-CD, respectively, formed hydrogels at room temperature.

In the later formulation, $\gamma$-CD aided the gel formation of triblock copolymer at a low concentration of PCL-PEG-PCL. Although PCL-PEG-PCL is one of the thermoresponsive copolymers that can turn into a gel state in response to mounting temperature, a higher concentration of copolymer solution is needed for this purpose. Furthermore, it seems even the concentrated solution of our synthesized copolymer with such a low PCL/PEG ratio, 1/5, cannot turn into a gel due to the short PCL blocks and insufficient hydrophobic interactions between polymer chains. We assume that the interaction within the PCL blocks hardly occurred prior to covering the long hydrophilic PEG blocks by $\gamma$-CD. Here, the inclusion complexes formed by $\gamma$-CD and PEG blocks of PCL-PEG-PCL triblock copolymers are thought to create small aggregates, which induce formation of a supramolecular polymer network, consequently resulting in the gelation of the solutions. ${ }^{[33]}$ In fact, the micellization of the PCL block is important in the gelation process. ${ }^{[34]}$ The hydrophobic interactions between the PCL blocks facilitate the formation of the polymer network. ${ }^{[35]}$ Therefore, the gelation of the aqueous solutions of PCL-PEGPCL triblock copolymers and $\gamma$-CD is the result of a cooperation of the inclusion complexation between $\gamma$-CD and PEG blocks and the micellization of the PCL blocks of the triblock copolymers.

In this study, for the $\mathrm{PCL}_{600}-\mathrm{PEG}_{6000}-\mathrm{PCL}_{600}$ copolymer with a PCL/PEG ratio of $1 / 5$ at concentrations about $20 \%(\mathrm{w} / \mathrm{v})$ of $\gamma$-CD and $10 \%(w / v)$ of copolymer, the SMGel was formed successfully in just $4 \mathrm{~s}$. This time is slightly more for the other formulation containing lower amounts of copolymer yet higher $\gamma$-CD: And 2.5\% (w/v) of copolymer and 25\% (w/v) of $\gamma$-CD. It affirmed the role of copolymer concentration on gelation time, which is critical for in situ forming drug delivery systems. Regarding these systems, if the gelation occurred with a delay, the dose-dumping phenomenon and its subsequent adverse reaction would emerge. Using the SMGel formulations, as the prepared system was administrated in its final shape, that is the gel state, the gelation time was not a very crucial parameter. However, in a case of sensitive drug molecules, which destabilize rapidly during preparations and by considering the importance of cost and time in the industry, the formulations that can turn into gel immediately are desirable.

\section{Swelling ratio}

Penetration of water into the porous structure of SMGel leads to its swelling. Figure 3 shows the swelling capacity of hydrogel in distilled water. The hydrogels exhibited good water-swelling ability such that after $15 \mathrm{~min}$, the weight of SMGel increased 1.5 times. We supposed that large PEG blocks and hydrophilic cavities of $\gamma$-CD induce water absorption into the SMGel. A large quantity of water increases the biocompatibility of such a system.

\section{Rheological properties of SMGel}

Representative curves of shear stress and logarithmic transformations of viscosity versus shear rate of formulation containing $10 \% \mathrm{w} / \mathrm{v}$ of copolymer and $20 \% \mathrm{w} / \mathrm{v}$ of $\gamma$-CD [Figures 4 and 5] all indicate the shear-thinning behavior of the prepared SMGel.

The prepared dexamethasone formulation easily passed through a 25 -gauge syringe at $25^{\circ} \mathrm{C}$ and was injectable. This is attributable to the thixotropic behavior of the SMGel. ${ }^{[36]}$ By elevating the shear rate, the viscosity of SMGel decreases. It facilitates the flow of

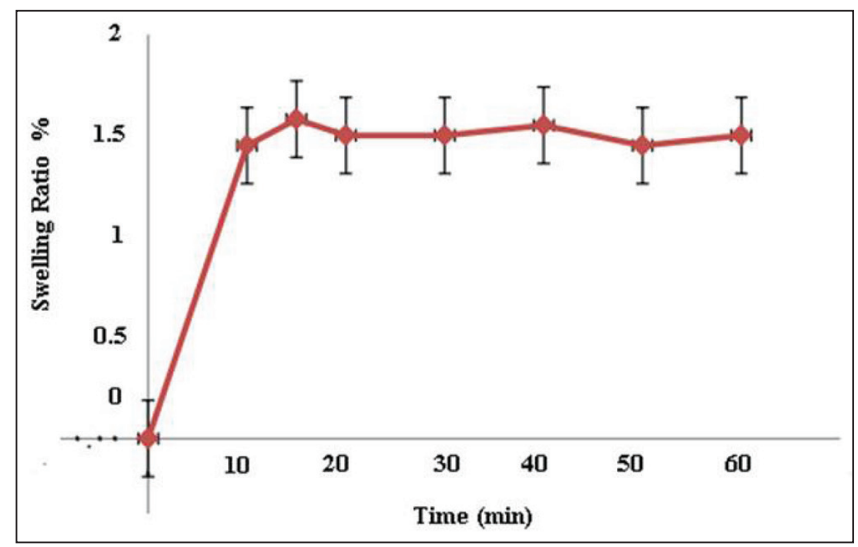

Figure 3: Swelling ratio of SMGels during $60 \mathrm{~min}$

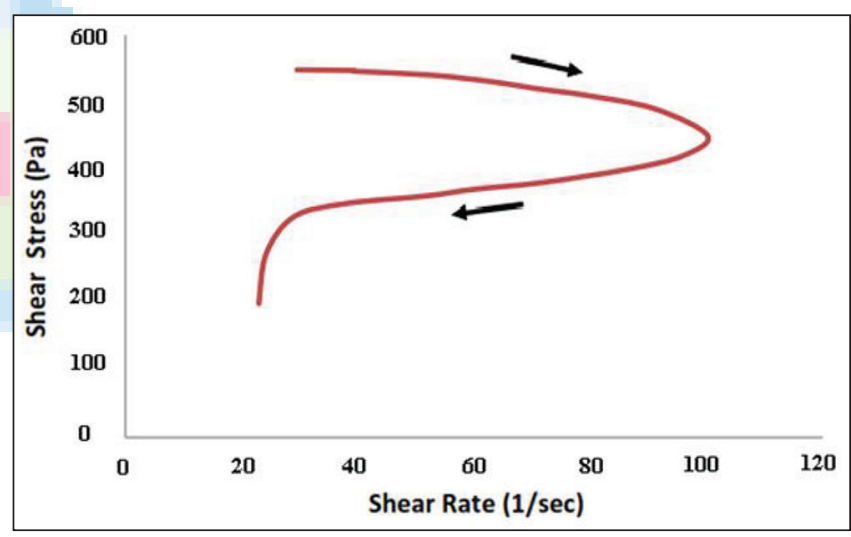

Figure 4: Thixotropic characteristics of SMGel composed of $10 \% \mathrm{w} / \mathrm{v}$ of copolymer and $20 \% \mathrm{w} / \mathrm{v}$ of $\gamma-\mathrm{CD}$

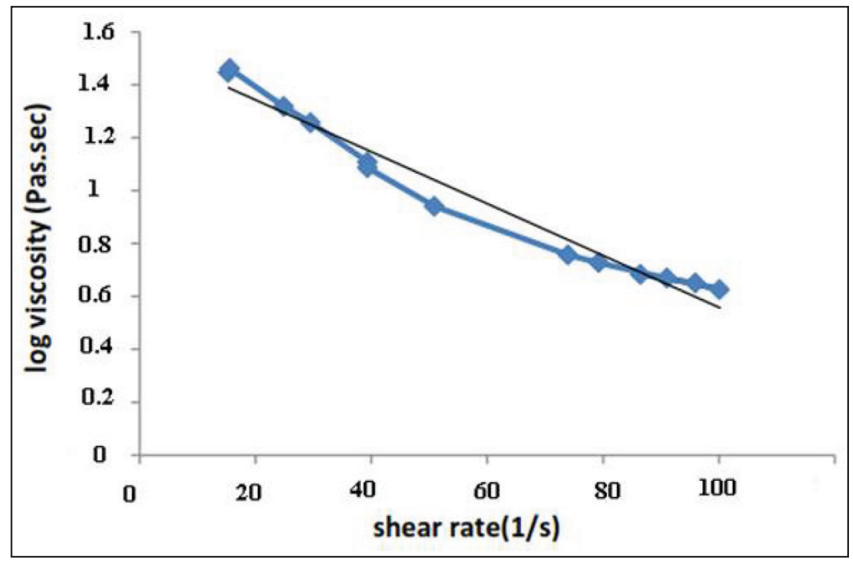

Figure 5: Logarithm of viscosity (Pa.sec) versus shear rate (1/s) for SMGel composed of $10 \% \mathrm{w} / \mathrm{v}$ of copolymer and $20 \% \mathrm{w} / \mathrm{v}$ of $\gamma-C D$ 
formulation through the needle. When there is no more stress on the system, it regains its initial viscose structure.

\section{SEM imaging}

The structural shape of the freeze-dried SMGel and the physical mixture of dexamethasone $/ \gamma-\mathrm{CD} /$ copolymer were analyzed by SEM.

As shown in Figure 6, in contrast to the physical mixture of the hydrogel component, the dehydrated SMGel exhibited porous, foam-like morphology.

\section{XRPD}

The $x$-ray powder patterns of the copolymer, $\gamma$-CD, dexamethasone, their physical mixture, and the SMGel formulations are shown in Figure 7.

Previously, it was shown that the refiection at $\mathrm{d}=4.46 \mathrm{~A}^{\circ}, 2 \theta=$ 19.8 is a characteristic peak, which is the identity of necklace-like structures. ${ }^{[25]}$

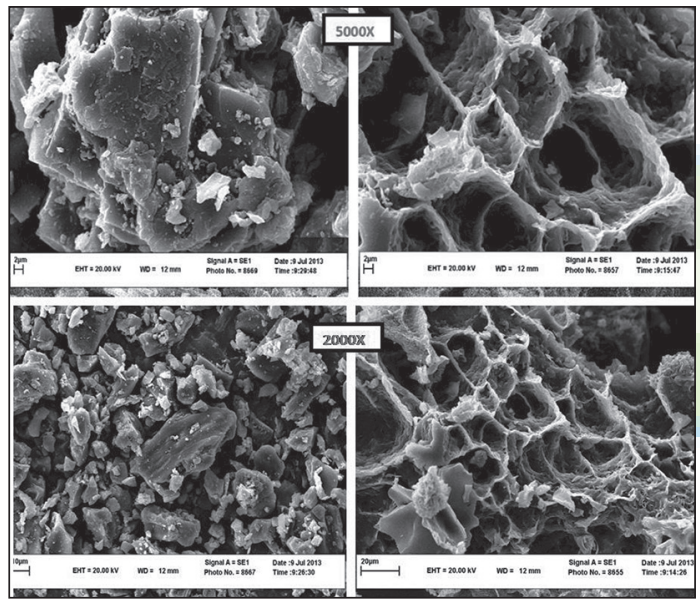

Figure 6: SEM image of freeze-dried hydrogel (right) and physical mixture of pure components (left)
As two polymer chains can be included within the large cavity of $\gamma$-CD, the degree of crystallinity of this SMGel is low and it shows more elasticity.

Therefore, in contrast to $\alpha$-CD inclusion complexes, $\gamma$-CD inclusion complexes does not exhibit a sharp peak at $\mathrm{d}=4.46 \mathrm{~A}^{\circ}$, $2 \theta=19.8$.

\section{Differential scanning calorimetry (DSC)}

The DSC experiment was performed to characterize the thermal behavior of SMGel as well as the physical mixture of the hydrogel component. The DSC thermogram of the copolymer, $\gamma$-CD, dexamethasone, as well as their physical mixture, and the dexamethasone-loaded SMGel is shown in Figure 8.

The endothermic peak related to copolymer was observed in the physical mixture of copolymer $/ \gamma-C D$, copolymer $/ \gamma-C D /$ dexamethasone, and also pure copolymer.

However, the endothermic peak in the SMGel system was completely disappeared. The results obtained suggest that the SMGel formulation was appropriately prepared.

\section{In vitro release}

Figure 9 shows the release profile of dexamethasone through the SMGel in PBS pH 7.4 at $37^{\circ} \mathrm{C}$.

As can be observed in the release profile, the formulation containing $0.1 \%$ dexamethasone released about $40-46 \%$ of the loaded drug after 23 days. However, the SMGel containing $0.5 \%$ dexamethasone released $100 \%$ of the drug up to 23 days.

Release of dexamethasone from the SMGel occurred slowly, with a slight burst release. Dexamethasone is a small molecule, so in addition to polymer degradation, diffusion occurs, as the main mechanism of release. ${ }^{[37]}$ It seems that the SMGel degradation started after approximately 23 days. On increasing

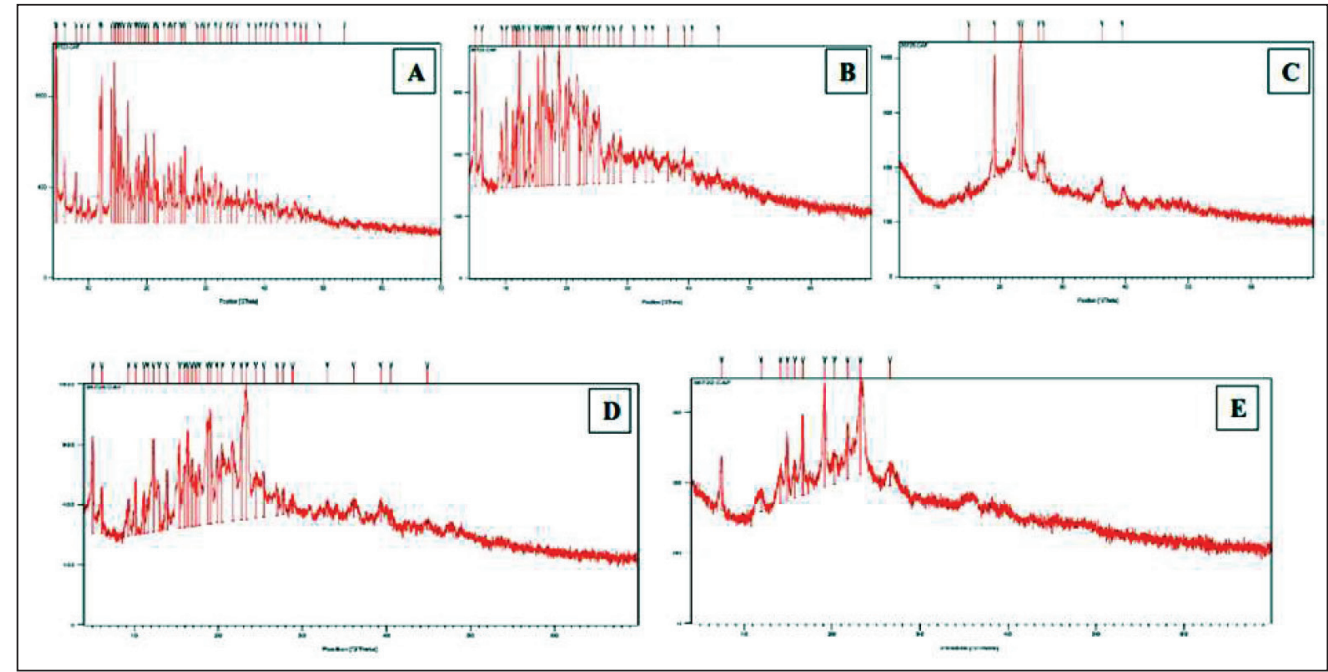

Figure 7: The x-ray powder pattern of dexamethasone (a), $\gamma$-CD (b), copolymer (c), physical mixture, (d) and dexamethasone-loaded SMGel (e) 


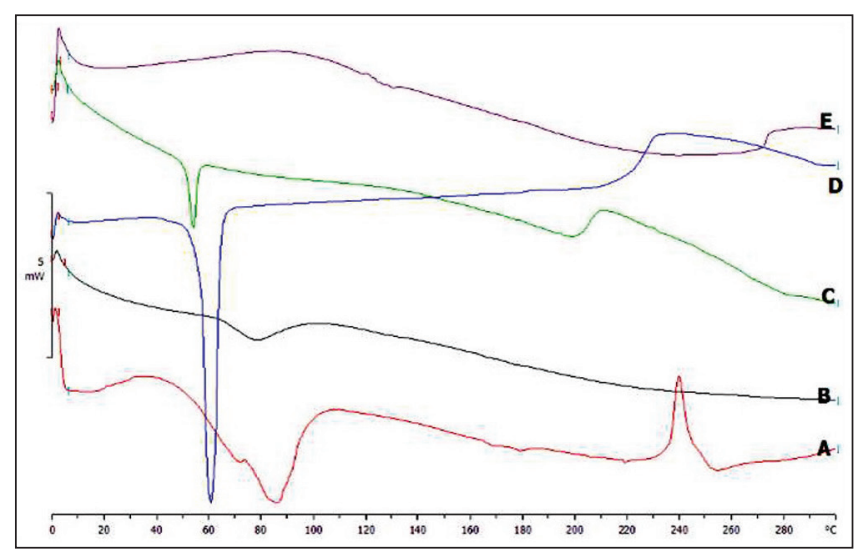

Figure 8: The DSC thermogram of dexamethasone (a), $\gamma-C D(b)$, physical mixture of dexamethasone/copolymer $/ \gamma-C D$ (c), copolymer (d), and dexamethasone-loaded SMGel (e)

the concentrations of the dexamethasone, the rate of release is increased significantly $(P<0.05)$ because of the higher concentration of the dexamethasone with high ionic charge within SMGel and, consequently, the higher water activity in the hydrogel matrix. ${ }^{[38]}$ In addition, bearing in mind Fick's diffusion equation, a higher concentration of solute causes faster release of it.

Table 3 indicates the kinetic profiles of dexamethasone that verified our hypothesis regarding the release mechanism. Considering the $\mathrm{R}^{2}$ associated with the Higuchi and zero order models, both diffusion and degradation played important roles in the dexamethasone release profiles. ${ }^{[39-41]}$

The Higuchi model was better fitted to obtain data of the release of drug, which is a small water-soluble molecule with high ionic charge. Reported slopes related to the rate of release indicated the rapid diffusion of drug molecules occurred at higher drug-loading concentration in approximately 23 days, which is before the time that visible erosion or degradation occurred in the formulations.

\section{CONCLUSION}

We have successfully developed SMGel self-assembled between PCL-PEG-PCL micelles and $\gamma$-CDs. The cooperative effect of coordination between complexation of PEG chains and $\gamma$-CDs and hydrophobic interaction of PCL blocks resulted in the formation of the network structure. We have clearly demonstrated the inclusion complex formation of the hydrogels by XRPD, SEM, and DSC studies. The hydrogel was thixotropic and could absorb large amounts of water, which made it promising for the preparation of a biocompatible drug delivery system.

Our SMGel design potentially allows for dexamethasone modalities into a single injectable, sustained delivery system, which is the focus of our future investigation.

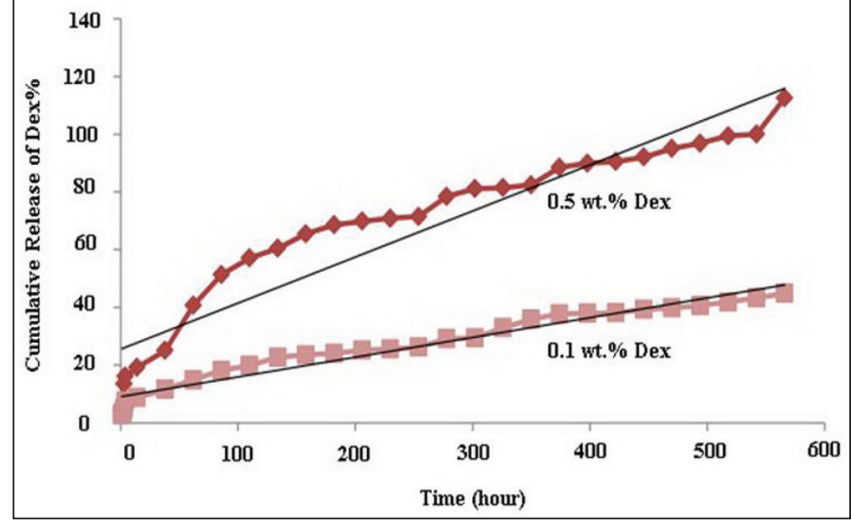

Figure 9: Release profile of dexamethasone-loaded SMGel composed of $10 \%(w / v)$ copolymer, $20 \%(w / v) \gamma-C D$, and $0.5 \%$ or $0.1 \%(w / v)$ dexamethasone

\begin{tabular}{|c|c|c|c|c|c|c|}
\hline \multicolumn{3}{|c|}{ Formulations } & \multicolumn{2}{|c|}{ Zero order } & \multicolumn{2}{|c|}{ Higuchi } \\
\hline $\begin{array}{l}\text { Dexamethasone } \\
\text { (\%) (w/v) }\end{array}$ & $\begin{array}{l}\text { Polymer } \\
(\%)(w / v)\end{array}$ & $\begin{array}{c}\gamma-C D \\
(\%) \\
(w / v)\end{array}$ & Slope & $\mathbf{R}^{2}$ & Slope & $\mathbf{R}^{2}$ \\
\hline $\begin{array}{l}0.1 \\
0.5\end{array}$ & $\begin{array}{l}10 \\
10\end{array}$ & $\begin{array}{l}20 \\
20\end{array}$ & $\begin{array}{l}0.068 \\
0.159\end{array}$ & $\begin{array}{l}0.953 \\
0.981\end{array}$ & $\begin{array}{l}1.768 \\
4.245\end{array}$ & $\begin{array}{l}0.988 \\
0.983\end{array}$ \\
\hline
\end{tabular}

Financial support and sponsorship

Nil.

Conflicts of interest

There are no conflicts of interest.

\section{REFERENCES}

1. Kim JK, Kim HJ, Chung JY, Lee JH, Young SB, Kim YH. Natural and synthetic biomaterials for controlled drug delivery. Arch Pharm Res 2013;37:60-8.

2. Patel GC, Dalwadi CA. Recent patents on stimuli responsive hydrogel drug delivery system. Recent Pat Drug Deliv Formul 2013;7:206-15.

3. Sabadini E, Egídio Fdo C, Cosgrove T. More on polypseudorotaxanes formed between poly(ethylene glycol) and $\alpha$-cyclodextrin. Langmuir 2013;29:4664-9.

4. Yu L, Ci T, Zhou S, Ding J. Sustained release of doxorubicin from a thermosensitive hydrogel. J Control Release 2013; 172:e53.

5. Wang W, Zhang P, Shan W, Gao J, Liang W. A novel chitosanbased thermosensitive hydrogel containing doxorubicin liposomes for topical cancer therapy. J Biomater Sci Polym Ed 2013;24:1649-59.

6. Lehn JM. Supramolecular Chemistry: Concepts and Perspectives. Weinheim: Wiley-VCH; 1995.

7. Zhu W, Li Y, Liu L, Chen Y, Xi F. Supramolecular hydrogels as a universal scaffold for stepwise delivering Dox and Dox/cisplatin loaded block copolymer micelles. Int J Pharm 2012;437:11-9.

8. Yan J, Ye Z, Chen M, Liu Z, Xiao Y, Zhang Y, et al. Fine tuning micellar core-forming block of poly(ethylene glycol)-blockpoly( $\square$-caprolactone) amphiphilic copolymers based on chemical 
modification for the solubilization and delivery of doxorubicin. Biomacromolecules 2011;12:2562-72.

9. Bender ML, Komiyama M. Cyclodextrin Chemistry. 96 Seiten, 14 Abb., 37 Tab. Berlin, Heidelberg, New York: Springer-Verlag; 1978.

10. Szejtli J. Cyclodextrins and their Inclusion Complexes. Budapest: Akademiai Kiado; 1982.

11. Uekama K, Hirayama F, Irie T. Cyclodextrin drug carrier systems. Chem Rev 1998;98:2045-76.

12. Li J, Harada A, Kamachi M. Sol-Gel transition during inclusion complex formation between $\alpha$-cyclodextrin and high molecular weight poly(ethylene glycol)s in aqueous solution. Polym J 1994;26:1019-26.

13. Wenz G, Han BH, Müller A. Cyclodextrin rotaxanes and polyrotaxanes. Chem Rev 2006;106:782-817.

14. Harada A. Cyclodextrin-based molecular machines. Acc Chem Res 2001;34:456-64.

15. Li J, Li X, Zhou Z, Ni X, Leong KW. Formation of supramolecular hydrogels induced by inclusion complexation between pluronics and $\alpha$-cyclodextrin. Macromolecules 2001;34:7236-7.

16. Jiao H, Goh SH, Valiyaveettil S. Inclusion complexes of multiarm poly(ethylene glycol) with cyclodextrins. Macromolecules 2002;35:1980-3.

17. Girardeau TE, Zhao T, Leisen J, Beckham HW, Bucknall DG. Solid inclusion complexes of $\alpha$-cyclodextrin and perdeuterated poly(oxyethylene). Macromolecules 2005;38:2261-70.

18. Yui N, Ooya T. Molecular mobility of interlocked structures exploiting new functions of advanced biomaterials. Chemistry 2006;12:6730-7.

19. Li J, Ni X, Leong KW. Injectable drug-delivery systems based on supramolecular hydrogels formed by poly(ethylene oxide) and alpha-cyclodextrin. J Biomed Mater Res A 2003;65:196-202.

20. Li J, Li X, Ni X, Wang X, Li H, Leong KW. Self-assembled supramolecular hydrogels formed by biodegradable PEO-PHBPEO triblock copolymers and alpha-cyclodextrin for controlled drug delivery. Biomaterials 2006;27:4132-40.

21. Li J, Yang C, Li HZ, Wang X, Goh SH, Ding JL, et al. Cationic supramolecules composed of multiple oligoethylenimine-grafted beta-cyclodextrins threaded on a polymer chain for efficient gene delivery. Adv Mater 2006;18:2969-74.

22. Jung $\mathrm{S}, \mathrm{Yi} \mathrm{H}$. Fabrication of chitosan-poly(ethylene glycol) hybrid hydrogel microparticles via replica molding and its application toward facile conjugation of biomolecules. Langmuir 2012;28:17061-70.

23. Abu Hashim II, Higashi T, Anno T, Motoyama K, Abd-EIGawad AE, El-Shabouri $\mathrm{MH}$, et al. Potential use of gamma-cyclodextrin polypseudorotaxane hydrogels as an injectable sustained release system for insulin. Int J Pharm 2010;392:83-91.

24. Higashi T, Tajima A, Motoyama K, Arima H. Cyclodextrin/ poly(ethylene glycol) polypseudorotaxane hydrogels as a promising sustained-release system for lysozyme. J Pharm Sci 2012;101:2891-9.

25. Staats HF, Leong KW. Polymer hydrogels: Chaperoning vaccines. Nat Mater 2010;9:537-8.

26. Yu J, Fan H, Huang J, Chen J. Fabrication and evaluation of reduction-sensitive supramolecular hydrogel based on cyclodextrin/polymer inclusion for injectable drug-carrier application. Soft Matter 2011;7:7386-94.

27. Hardman J, Limbird L, Molinoff P, Ruddon R, Gliman A. Goodman and Gilman's the Pharmacological Basis of Therapeutics. $9^{\text {th }}$ ed. New York: McGraw-Hill; 1996.

28. Ma D, Zhang LM. Supramolecular gelation of a polymeric prodrug for its encapsulation and sustained release. Biomacromolecules 2011;12:3124-30.

29. Khodaverdi E, Akbari A, Tekie FS, Mohajeri SA, Zohuri G, Hadizadeh F. Sustained delivery of amphotericin B and vancomycin hydrochloride by an injectable thermogelling tri-block copolymer. PDA J Pharm Sci Technol 2013;67:135-45.

30. Jeong B, Choi YK, Bae YH, Zentner G, Kim SW. New biodegradable polymers for injectable drug delivery systems. J Control Release 1999;62:109-14.

31. Wöhl-Bruhn S, Bertz A, Harling $S$, Menzel $H$, Bunjes $H$. Hydroxyethyl starch-based polymers for the controlled release of biomacromolecules from hydrogel microspheres. Eur J Pharm Biopharm 2012;81:573-81.

32. Khodaverdi E, Kheirandish F, MirzazadehTekieh FS Khashayarmanesh BZ, Hadizadeh F, Moallemzadeh Haghighi $\mathrm{H}$. Preparation of a sustained release drug delivery system for dexamethasone by a thermosensitive, in situ forming hydrogel for use in differentiation of dental pulp. ISRN Pharm 2013;2013:983053.

33. Huh KM, Cho YW, Chung H, Kwon IC, Jeong SY, Ooya T, et al. Supramolecular hydrogel formation based on inclusion complexation between poly(ethylene glycol)-modified chitosan and alpha-cyclodextrin. Macromol Biosci 2004;4:92-9.

34. Zhao SP, Zhang LM, Ma D. Supramolecular hydrogels induced rapidly by inclusion complexation of poly(epsilon-caprolactone)poly(ethylene glycol)-poly(epsilon-caprolactone) block copolymers with alpha-cyclodextrin in aqueous solutions. J Phys Chem B 2006;110:12225-9.

35. Ni X, Cheng A, Li J. Supramolecular hydrogels based on selfassembly between PEO-PPO-PEO tri-block copolymers and alpha-cyclodextrin. J Biomed Mater Res A 2009;88:1031-6.

36. Li X, Li J. Supramolecular hydrogels based on inclusion complexation between poly(ethylene oxide)-b-poly (epsiloncaprolactone) diblock copolymer and alpha-cyclodextrin and their controlled release property. J Biomed Mater Res A 2008;86:1055-61.

37. Khodaverdi E, Mirzazadeh Tekie FS, Hadizadeh F, Esmaeel H, Mohajeri SA, Sajadi Tabassi SA, et al. Hydrogels composed of cyclodextrin inclusion complexes with PLGA-PEG-PLGA triblock copolymers as drug delivery systems. AAPS PharmSciTech 2014;15:177-88.

38. Tabata Y, Nagano A, Ikada Y. Biodegradation of hydrogel carrier incorporating fibroblast growth factor. Tissue Eng 1999;5: 127-38.

39. Möckel JE, Lippold BC. Zero-order drug release from hydrocolloid matrices. Pharm Res 1993;10:1066-70.

40. Masaro L, Zhu XX. Physical models of diffusion for polymer solutions, gels and solids. Prog Polym Sci 1999;24:731-75.

41. Lin CC, Metters AT. Hydrogels in controlled release formulations: Network design and mathematical modeling. Adv Drug Deliv Rev 2006;58:1379-408. 